\title{
Tanshinone IIA inhibits leukemia THP-1 cell growth by induction of apoptosis
}

\author{
JIA-JUN LIU ${ }^{1}$, YONG ZHANG ${ }^{2}$, DONG-JUN LIN ${ }^{1}$ and RUO-ZHI XIAO ${ }^{1}$ \\ ${ }^{1}$ Department of Hematology, The Third Affiliated Hospital of Sun Yat-sen University; ${ }^{2}$ Department of \\ Nuclear Medicine, The Third Hospital of Sun Yat-Sen University, Guangzhou 510630, P.R. China
}

Received October 14, 2008; Accepted November 18, 2008

DOI: 10.3892/or_00000326

\begin{abstract}
Tanshinone IIA, a diterpene quinone extracted from the traditional herbal medicine, Salvia miltiorrhiza Bunge, has been reported to have anti-tumor effects on a large variety of cancer cells. The present study was undertaken to investigate the in vitro antiproliferation and apoptosis inducing effects of Tanshinone IIA on leukemia THP-1 cell lines and its mechanisms of action. MTT assay was used to detect the cell growth inhibitory rate; cell apoptotic rate and the mitochondrial membrane potential $(\Delta \psi \mathrm{m})$ were investigated by flow cytometry (FCM), apoptotic morphology was observed by Hoechst 33258 staining and DNA fragmentation analysis. The expression of caspase- 3 and different apoptosis modulators were analyzed by Western blotting. The results revealed that Tanshinone IIA inhibited the growth of THP-1 cells and caused significant apoptosis, the suppression was both in time- and dose-dependent manner. After treatment by Tanshinone IIA for $48 \mathrm{~h}$, the percentage of disruption of $\Delta \psi \mathrm{m}$ gradually increased in a dose-dependent manner along with marked changes of cell apoptosis. Western blotting showed cleavage of the caspase-3 zymogen protein $(32-\mathrm{kDa})$ with the appearance of its $20-\mathrm{kDa}$ subunit and a dose-dependent cleavage of PARP, with the appearance of $89-\mathrm{kDa}$ fragment; The expression of $\mathrm{Bcl}-2$ and survivin was down-regulated remarkably while Bax expression was up-regulated concurrently after the cells were treated with Tanshinone IIA for $48 \mathrm{~h}$. We therefore conclude that Tanshinone IIA has significant growth inhibition effects on THP-1 cells by induction of apoptosis, and that Tanshinone IIA-induced apoptosis on THP-1 cells is mainly related to the disruption of $\Delta \psi \mathrm{m}$ and activation of caspase-3 as well as down-regulation of anti-apoptotic protein Bcl-2, survivin and up-regulation of pro-apoptotic protein $\mathrm{Bax}$. The results indicate that
\end{abstract}

Correspondence to: Professor Dong-Jun Lin, Department of Hematology, The Third Affiliated Hospital of Sun Yat-sen University, Guangzhou 510630, P.R. China

E-mail: lindongjun0168@163.com

Key words: tanshinone IIA, apoptosis, leukemia
Tanshinone IIA may serve as a potential anti-leukemia reagent.

\section{Introduction}

Recently, the use of herbal medicines to prevent the development as well as recurrence of a large variety of malignant diseases has become widely accepted as a realistic option for the treatment of malignant disease. There has been intense effort not only to identify new herbal medicines but also to understand how the existing constituents exhibit their activities (1).

Danshen (Salvia miltiorrhiza Bunge) is a widely used Chinese herbal medicine; its extracts contain diterpene quinine and phenolic acid derivatives, including tanshinone (I, IIA and IIB), cryptotanshinone, isocryptotanshinone, miltirone, tanshinol (I and II) and salviol (2). Tanshinone IIA is a derivative of phenanthrene-quinone isolated from Danshen (Fig. 1); it has anti-oxidant properties, inhibiting the association of lipid peroxidation products with DNA by breaking the chain reactions of peroxidation by scavenging lipid free radicals (3-5). Recent studies have shown that Tanshinone IIA has significant anti-proliferation effects by inducing apoptosis against multiple human cancer cell lines such as human breast cancer (6) and hepatocellular carcinoma (7).

Apoptosis (programmed cell death), a form of cell death defined by a characteristic set of morphological and biochemical changes which is a highly regulated process that involves the activation of a series of cellular events leading to cell death, plays an important role in the prevention of cancer development, and impaired apoptosis is now recognized to be a key step in tumorigenesis (8). Apoptosis is mediated through at least three major pathways, which are regulated by the death receptors, mitochondria and endoplasmic reticulum. Activation of apoptosis pathways is a key mechanism by which cytotoxic drugs kill tumor cells, and defects in apoptosis signalling contribute to tumor cell drug resistance $(9,10)$. Thus, induction of apoptosis has now been considered as an important method of assessment for the clinical effectiveness of many anti-tumor drugs and a significant index for the selection of new anti-tumor drugs $(10,11)$.

Though Tanshinone IIA has been proved to be very effective in treating a variety of malignancies, many of its anti-tumor mechanisms have not been demonstrated. Currently there is no detailed laboratory evidence showing the 
mechanisms of Tanshinone IIA on leukemic THP-1 cells. In order to clarify some of its anti-leukemia mechanisms, we investigated the apoptotic effects of various concentrations of Tanshinone IIA (10-50 $\mu \mathrm{mol} / 1)$ on THP-1 cells in vitro, and detected the expressions of caspase- 3 as well as some gene expression that related to apoptosis to provide laboratory evidence of Tanshinone IIA for its mechanisms in the treatment of leukemia.

\section{Materials and methods}

Reagent. Tanshinone IIA, isolated from Salvia miltiorrhiza Bunge, was provided by Professor Pei-Qing Liu, Institute of Pharmacy College, Sun Yat-sen University. Hoechst 33258 was purchased from Sigma Company. The antibodies used in this study, anti-Bcl-2, Bax, Bid, Bad and Bak as well as antisurvivin were purchased from Santa Cruz Company (Germany). Antibodies against caspase-3 and poly (ADPribose) polymerase (PARP) were from Upstate Inc.

Cell culture. Human leukemia cell line THP-1 T-cells (purchased from Shanghai Rui-jin hospital) were cultured in RPMI-1640 medium supplemented with $10 \%$ heat-inactivated calf serum, and $100 \mathrm{U} / \mathrm{ml}$ penicillin in a humidified $5 \%$ incubator at $37^{\circ} \mathrm{C}$. Cells were passaged twice weekly and routinely examined for mycoplasma contamination.

Cell growth inhibitory rate. Cell growth inhibitory rate was assayed using the microculture tetrazolium method. Briefly, $2 \times 10^{5}$ cells/well were dispensed within 96 -well culture plates in $100 \mathrm{ml}$ volumes. Then different concentrations of Tanshinone IIA $(10,20,30,40$ and $50 \mu \mathrm{mol} / \mathrm{l})$ were put in different wells. Every one of the concentrations above was regarded as one treated group while the control group contained no Tanshinone IIA. Each of the treated or control group contained 6 parallel wells. After culture plates were incubated for $0,24,48$ and $72 \mathrm{~h}, 20 \mu \mathrm{l}$ of MTT working solution was added and then incubated continuously for $4 \mathrm{~h}$. All culture medium supernatant was removed from the wells after centrifugation and replaced with $100 \mu 1$ of DMSO. Following thorough solublization, the absorbance (A value) of each well was measured using a microculture plate reader at $570 \mathrm{~nm}$. Cell inhibitory rate was calculated according to the formula: inhibitory rate $=100 x$ (A value of control group-A value of treated group)/A value of control group. The 50\% inhibitory concentration $\left(\mathrm{IC}_{50}\right)$ was determined from doseresponse data from at least 3 indepen-dent experiments.

Flow cytometry analysis for cell apoptosis. For FCM analysis, $2 \times 10^{6}$ cells treated with different concentrations of Tanshinone IIA were collected, pelleted, washed with PBS, and fixed in $75 \%$ ethanol at $-20^{\circ} \mathrm{C}$ overnight. Prior to analysis, cells were washed again with PBS and resuspended and treated with RNase $200 \mathrm{mg} / \mathrm{l}$ for $30 \mathrm{~min}$ at $37^{\circ} \mathrm{C}$, cells were then incubated with $20 \mathrm{mg} / \mathrm{l} \mathrm{PI}$ in the darkness for $15 \mathrm{~min}$. Then, the suspension was passed through a nylon mesh filter and analyzed using flow cytometry (Becton-Dickinson). All data were collected and analyzed by lysis II software (BectonDickinson). The experiments were repeated 3 times and the results were presented as mean $\pm \mathrm{SD}$.

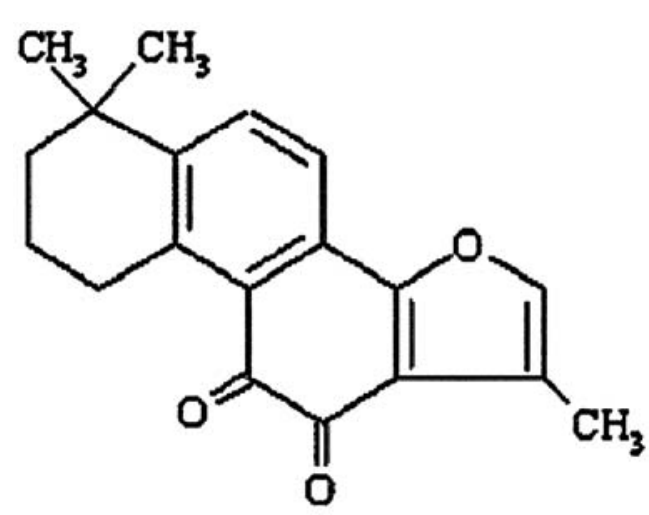

Figure 1. Molecular structure of Tanshinone IIA.

DNA fragmentation assay. Apoptosis was confirmed by detection of fragmentation of chromosomal DNA with the classic DNA ladder method. Briefly, $2 \times 10^{6}$ cells were immersed in cytolysis buffer and incubated for $3 \mathrm{~h}$ at $50^{\circ} \mathrm{C}$. DNA was extracted with phenol-chloroform, precipitated in $1 / 10$ volume of $\mathrm{NaAc} 2 \mathrm{~mol} / \mathrm{l}$ and 2 volumes of ethanol at $-20^{\circ} \mathrm{C}$ overnight, recovered by centrifugation at $1000 \mathrm{x}$ g for $30 \mathrm{~min}$ at $4^{\circ} \mathrm{C}$, and then resuspended in TE buffer. RNase A was then added at a concentration of $200 \mathrm{mg} / \mathrm{l}$, then the treated extract was incubated at $37^{\circ} \mathrm{C}$ for $30 \mathrm{~min}$ and electrophoresed on a $1.2 \%$ agarose gel.

Hoechst 33258 staining. Hoechst 33258 (purchased from Sigma Company) staining was used to observe the apoptotic morphology of THP-1 cells especially after the cells treated with Tanshinone IIA for $48 \mathrm{~h}$. Cells were fixed with $4 \%$ formaldehyde in phosphate-buffered saline (PBS) for $10 \mathrm{~min}$, stained by Hoechst $33258(10 \mathrm{mg} / \mathrm{l})$ for $1 \mathrm{~h}$, and then subjected to fluorescence microscopy.

Analysis of the mitochondrial membrane potential $(\Delta \psi m)$. The mitochondrial membrane potential $(\Delta \psi \mathrm{m})$ was measured by FCM using the intramitochondrial dye JC-1 (Alexis Biochemical Co, Germany) after THP-1 cells treated with Tanshinone IIA for $48 \mathrm{~h}$. The detection procedure was performed according to the manufacturer's instructions. Data were converted to dot plots using CellQuest software (BectonDickinson).

Western blot analysis. For Western blot analysis, $2 \times 10^{6}$ cells were washed with ice-cold PBS twice and lysed for $30 \mathrm{~min}$ at $4^{\circ} \mathrm{C}$, then debris was removed by centrifugation for $15 \mathrm{~min}$ at $15,000 \mathrm{x} \mathrm{g}$ at $4^{\circ} \mathrm{C}$, and equivalent amounts of protein were separated by $10 \%$ SDS-PAGE and transferred onto nitrocellulose filter. The filters were first stained to confirm uniform transfer of all samples and then incubated in blocking solution for $2 \mathrm{~h}$ at room temperature. The filters were reacted firstly with monoclonal antibody (anti-caspase-3 and anti-PARP as well as anti-Bcl-2, Bid, Bad, Bak and Bax as well as survivin) at a dilution of 1:1000 for $2 \mathrm{~h}$, followed by extensive washes with PBS twice and TBST twice. Filters were then incubated with 1:1000 diluted horseradish peroxidase-conjugated secondary antibody and washed with TBST. As an internal control, $\beta$-actin was also detected. The 


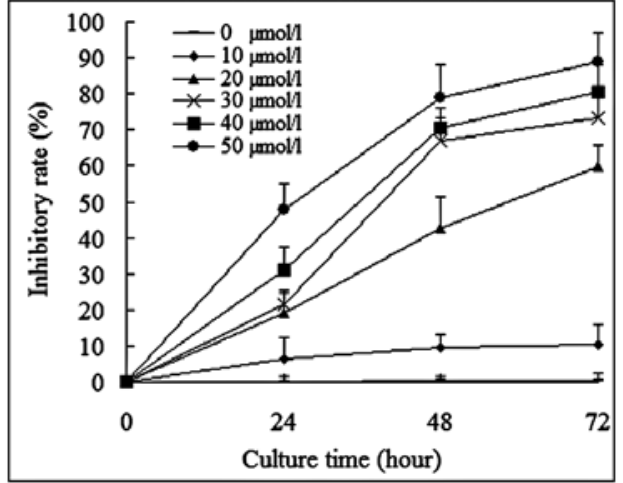

Figure 2. Cell growth inhibitory rate caused by Tanshinone IIA. After THP-1 cells were treated with different concentrations of Tanshinone IIA, MTT assay was used to detect cell growth inhibitory rate as described in Materials and methods. The inhibitory rate of Tanshinone IIA between $40-50 \mu \mathrm{mol} / 1$ is much higher than that of lower concentrations of Tanshinone IIA $(\mathrm{p}<0.01)$.

immunoreactive proteins were detected using an ECL Western blotting detection system.

Statistical analysis. All experiments were performed in triplicate and the results were expressed as mean \pm SD. Statistical analysis were performed with a Student's t-test using SAS 6.12 software. Statistical significance was accepted at the level of $\mathrm{p}<0.05$.

\section{Results}

Cell growth inhibition caused by Tanshinone IIA. Tanshinone IIA $(10 \mu \mathrm{mol} / \mathrm{l})$ had little inhibitory effect on THP-1 cells, but it inhibited the proliferation of THP-1 cells significantly at a higher concentration, especially when the concentration was over $30 \mu \mathrm{mol} / \mathrm{l}$. The inhibitory rate of Tanshinone IIA between $40-50 \mu \mathrm{mol} / 1$ is much higher than that of lower concentrations of Tanshinone IIA $(\mathrm{p}<0.01)$ (Fig. 2). The $\mathrm{IC}_{50}$ values after 24,48 and $72 \mathrm{~h}$ of treatment were $44.9,35.2$ and $21.3 \mu \mathrm{mol} / 1$.

Cell apoptosis caused by Tanshinone IIA. As shown in Fig. 3, Tanshinone IIA (>20 $\mu \mathrm{mol} / \mathrm{l})$ induced apoptosis when cultured with THP-1 cells after 24-72 h. The percentage of apoptotic cells was gradually increased in a time- and dosedependent manner. Tanshinone IIA at $50 \mu \mathrm{mol} / 1$ caused an apoptotic rate much higher $(>50 \%)$ than that of lower concentrations of Tanshinone IIA $(\mathrm{p}<0.05)$.

DNA fragmentation analysis. The intergrity of DNA was assessed by agarose gel electrophoresis. Incubation of THP-1 cells with Tanshinone IIA at $20-50 \mu \mathrm{mol} / 1$ for $72 \mathrm{~h}$ elicited a characteristic 'ladder' of DNA fragments representing integer multiples of the internucleosomal DNA length ( 180-200 bp) (Fig. 4).

Morphology of cell apoptosis. Cells were treated with different concentrations of Tanshinone IIA for $72 \mathrm{~h}$, then harvested and observed by Hoechst staining. No remarkable apoptotic

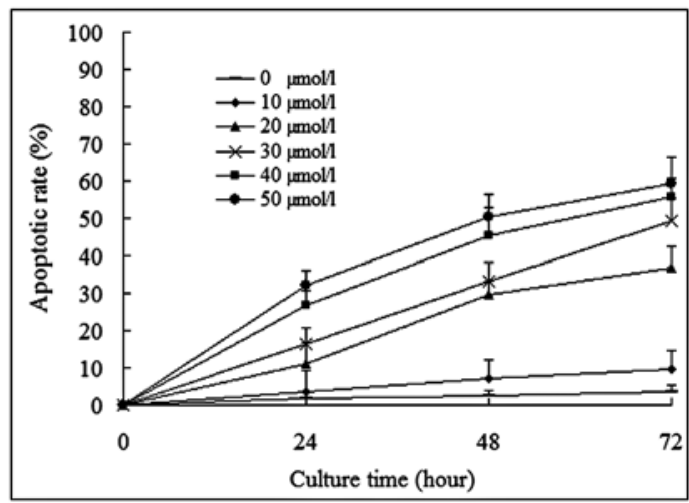

Figure 3. Cell apoptotic rate caused by Tanshinone IIA. After THP-1 cells were treated with different concentrations of Tanshinone IIA, cell apoptosis was analyzed by FCM. Tanshinone IIA $(>20 \mu \mathrm{mol} / \mathrm{l})$ induced apoptosis when cultured with THP-1 cells after 24-72 h. The percentage of apoptotic cells was gradually increased in a time- and dose-dependent manner. The percentage of apoptosis was high and over $50 \%$ when the cells were treated with $50 \mu \mathrm{mol} / 1$ Tanshinone IIA for $72 \mathrm{~h}$.

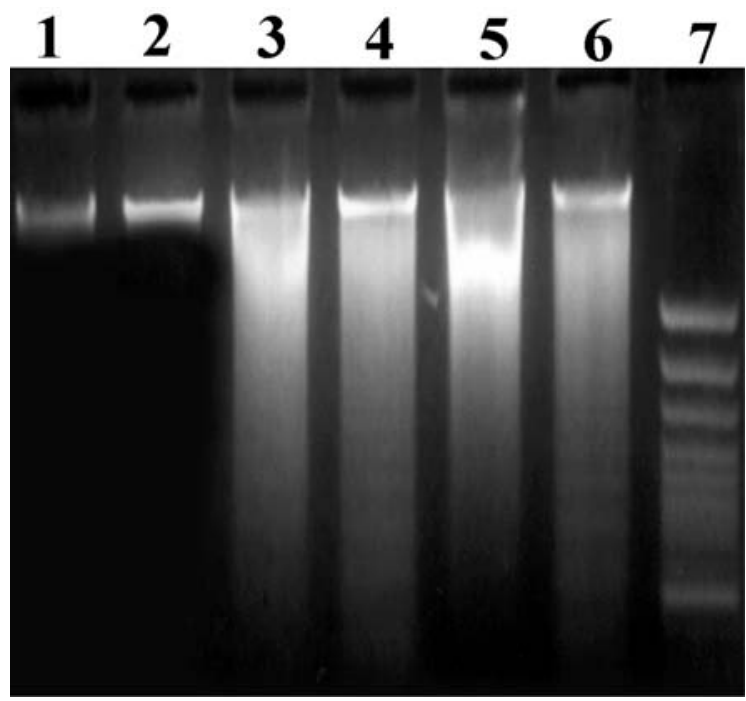

Figure 4. DNA fragmentation analysis. After cells were incubated with different concentrations of Tanshinone IIA for $72 \mathrm{~h}$, apoptosis was confirmed by detection of fragmentation of chromosomal DNA with the classic DNA ladder method. As shown in Fig. 4, DNA ladder was observed clearly when the Tanshinone IIA concentrations were $>20 \mu \mathrm{mol} / 1$. Lanes 1 , 2, 3, 4, 5 and 6 and were $0,10,20,30,40$ and $50 \mu \mathrm{mol} / 1$ Tanshinone IIA. Lane 7, DNA Marker.

morphology was observed after the cells were treated with $0 \mu \mathrm{mol} / \mathrm{l}$ (control) and $10 \mu \mathrm{mol} / \mathrm{l}$ (Fig. 5A and B). Apoptotic cells gradually increased when cells were treated by $20 \mu \mathrm{mol} / 1$ and $30 \mu \mathrm{mol} / 1$ Tanshinone IIA (Fig. 5C and D). Tanshinone IIA (40 and $50 \mu \mathrm{mol} / \mathrm{l}$ ) caused typical cell apoptotis (Fig. 5E and F). Marked morphological changes of cell apoptosis such as condensation of chromatin and nuclear fragmentations were found clearly using Hoechst 33258 staining. Apoptotic cells gradually increased in a dose-dependent manner in Tanshinone IIA treated cells.

Variation of caspase-3 activity. After treatment for $72 \mathrm{~h}$, the cleavage of procaspase-3 was detected by Western blotting. The results revealed that caspase- 3 was activated, as measured 

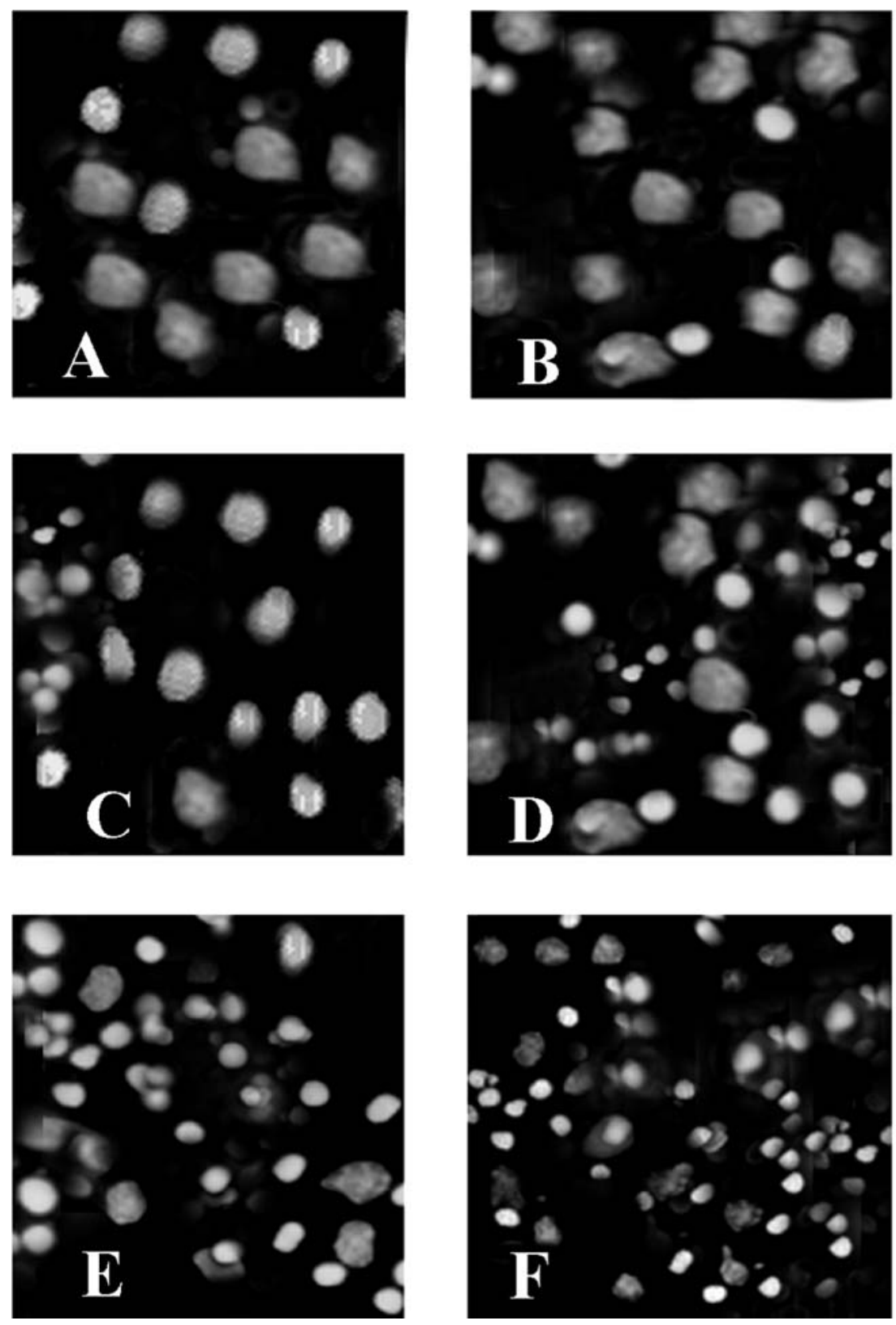

Figure 5. Cell apoptosis observed by Hoechst 33258 staining (x200). After the cells had been exposed to different concentrations of Tanshinone IIA for $72 \mathrm{~h}$, Hoechst 33258 staining was used to observe the morphology of cell apoptosis. Apoptotic cells gradually increased in a dose-dependent manner when the concentrations of Tanshinone IIA was over $20 \mu \mathrm{mol} / 1$. Marked morphological changes of cell apoptosis including condensation of chromatin and nuclear fragmentation were clearly observed. (A) Control (0 $\mu \mathrm{mol} / 1)$; (B) $10 \mu \mathrm{mol} / 1$; (C) $20 \mu \mathrm{mol} / 1$; (D) $30 \mu \mathrm{mol} / 1$; (E) $40 \mu \mathrm{mol} / 1$ and (F) $50 \mu \mathrm{mol} / 1$.

by the loss of caspase- 3 proenzyme $(32 \mathrm{kDa})$ and the appearance of its $17 \mathrm{kDa}$ subunit, after the cells had been exposed to Tanshinone IIA (>20 $\mu \mathrm{mol} / \mathrm{l}$ ) (Fig. 6A). Caspase-3 activation was found to increase concomitantly with increased concentration of Tanshinone IIA treatment. To confirm Tanshinone IIA induced activation of caspase- 3 , the cleavage of poly (ADP-ribose) polymerase (PARP), a known substrate of caspase-3, was also examined by Western blotting. As shown in Fig. 6B, Tanshinone IIA treatment caused a dose-dependent cleavage of PARP, with the appearance of $89-\mathrm{kDa}$ fragment and disappearance of the intact 116-kDa PARP (Fig. 6B).

Disruption of the $\Delta \psi m$. The changes in the membrane potential of the mitochondria in Tanshinone IIA treated cells were examined after the cells were treated for $48 \mathrm{~h}$. The results showed that the cells lost their mitochondrial membrane potential following Tanshinone IIA treatment. After Tanshinone IIA treatment for $48 \mathrm{~h}$, the cells exhibited a significant alterations in $\Delta \psi \mathrm{m}$, and the percentage of disruption of $\Delta \psi \mathrm{m}$ gradually increased in a dose-dependent manner (Fig. 7). This suggests that Tanshinone IIA induced apoptosis involves the mitochondrial signaling pathway.

Western blot analysis of Bcl-2 family members and survivin expression. After Tanshinone IIA ( $>20 \mu \mathrm{mol} / \mathrm{l})$ treatment for $72 \mathrm{~h}$, cell apoptosis was found clearly by using Hoechst staining and DNA Fragmentation Analysis. To determine whether apoptosis related gene expression might play roles in this event, we detected the expression of $\mathrm{Bcl}-2$ family members such as Bcl-2, Bax, Bid, Bad and Bak as well as the 


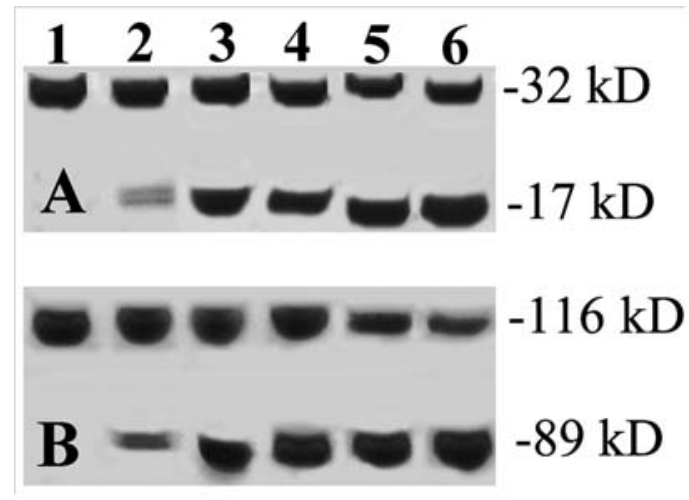

Figure 6. Western blot analysis of caspase-3 PARP. Caspase-3 was activated by the loss of caspase-3 proenzyme (32-kDa) and the appearance of its $17-\mathrm{kDa}$ subunit (A) after the cells exposed to Tanshinone IIA for $72 \mathrm{~h}$. Tanshinone IIA treatment also caused a dose-dependent cleavage of PARP, with the appearance of 89-kDa fragment (B). Lane 1, Control. Lanes 2, 3, 4, 5 and 6 were $10,20,30,40$ and $50 \mu \mathrm{mol} / 1$ Tanshinone IIA.

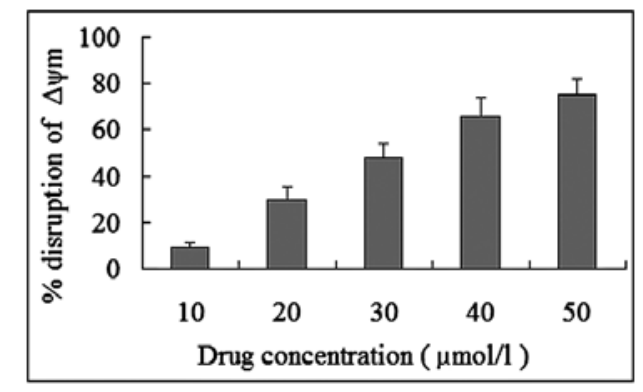

Figure 7. Disruption of the $\Delta \psi \mathrm{m}$. After Tanshinone IIA treatment for $48 \mathrm{~h}$, the cells exhibited a significant alteration in $\Delta \psi \mathrm{m}$, and the percentage of disruption of $\Delta \psi \mathrm{m}$ gradually increased in a dose-dependent manner.

expression of survivin after the cells were treated by Tanshinone IIA for $48 \mathrm{~h}$. Western blot analysis revealed that Bcl-2 and survivin expression was down-regulated while Bax expression was up-regulated concomitantly, and there was no variation of other Bcl-2 family members (Fig. 8).

\section{Discussion}

In recent years, the use of herbal medicines to prevent the development or recurrence of cancers has become widely accepted as a realistic option for the treatment of malignant disease and herbal medicines have been proved to play an important role in integrative cancer treatment (12). Tanshinone IIA (as shown in Fig. 1), a derivative of phenanthrene-quinone isolated from Danshen, is now widely used in the treatment of inflammatory and cardiological disease. Previous studies have shown that tanshinone IIA has a large variety of pharmacological activities such as inhibition of clotting (13), inhibition of NO synthase (14) and dosedependent inhibition on the basic fibroblast growth factor (bFGF)-induced human Smooth muscle cell (SMC) proliferation (15). Recent data have demonstrated that tanshinone IIA has anti-cancer activities on a large variety of cancer cells including solid tumor $(6,7)$ as well as certain type of leukemia cells (16).

Acute lymphoid leukemia (ALL) is the main type of leukemia in children, though $\sim 80 \%$ of ALL children can
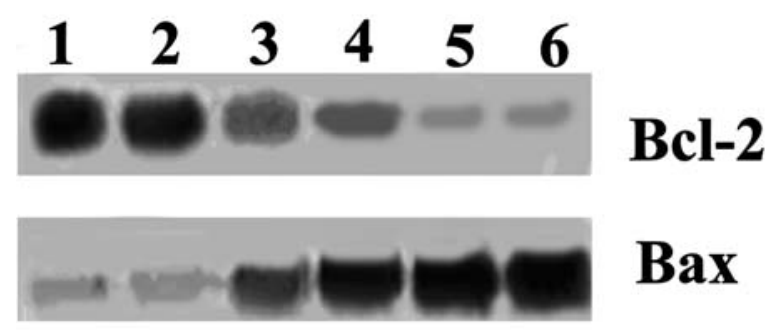

\section{Bax}

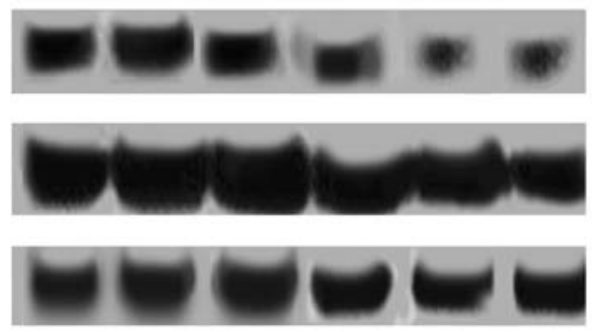

\section{Survivin}

\section{Bak}

\section{Bad}

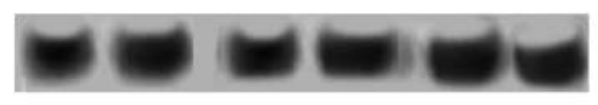

Bid

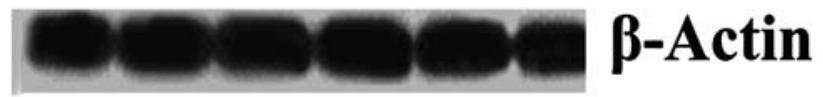

Figure 8. Western blot analysis of apoptosis related modulators. After the cells had been treated with Tanshinone IIA for $48 \mathrm{~h}$, the expressions of Bcl-2 family and survivin was detected by Western blotting. The expression of Bcl-2 and survivin was down-regulated while Bax expression was upregulated, and the expression of other Bcl-2 family members including Bak, Bid and Bad remained constant before and after apoptosis occurred. Lane 1, Control. Lane 2, 3, 4, 5 and 6 were 10, 20, 30, 40 and $50 \mu \mathrm{mol} / 1$ Tanshinone IIA.

reach complete remission and will be long-term survivor with current treatment protocols (17), the prognosis of many individuals such as Philadelphia chromosome positive $(\mathrm{Ph}+)$ ALL and HTLV-I-associated adult T-cell leukemia is still very poor $(18,19)$. Thus, there is a permanent need to find new anti-leukemia drugs and effective therapies for the clinical treatment of myeloid leukemia.

In this study, we found that Tanshinone IIA inhibited the growth of THP-1 cells and caused apoptosis significantly, the suppression was both in time- and dose-dependent manner. Marked changes of cell apoptosis were observed very clearly after the cells had been exposed to Tanshinone IIA for $72 \mathrm{~h}$. Western blotting showed cleavage of the caspase-3 zymogen protein $(32-\mathrm{kDa})$ with the appearance of its $20-\mathrm{kDa}$ subunit when apoptosis occurred. The expression of $\mathrm{Bcl}-2$ and survivin was down-regulated remarkably while Bax expression was up-regulated concurrently after the cells were treated with Tanshinone IIA for $48 \mathrm{~h}$. We therefore conclude that Tanshinone IIA has significant antiproliferation effects on THP-1 cells by induction of apoptosis, and that Tanshinone IIA induced apoptosis on THP-1 cells is mainly related to the disruption of $\Delta \psi \mathrm{m}$ and activation of caspase-3 as well as down-regulation of anti-apoptotic protein Bcl-2 and survivin as well as up-regulation of pro-apoptotic protein Bax. Our data indicated that the Tanshinone IIA-induced apoptosis on THP-1 cells mainly involved the mitochondrial signaling pathway. The results revealed that Tanshinone IIA may serve as a potential anti-leukemia reagent. 
The Bcl-2 family consists of about 20 homologues of important apoptotic regulators of programmed cell death. This family of proteins now includes both anti-apoptotic molecules such as Bcl-2, and pro-apoptotic molecules such as Bax (20). Cancers with high levels of Bcl-2 and Bcl-XL proteins are resistant to drug-induced apoptosis in a wide spectrum of chemotherapeutic agents, so Bcl-2 as well as Bcl-XL have become attractive targets for designing new anticancer drugs (21). Pro-apoptotic members of the Bcl-2 family, especially Bax and Bid, play important roles in drug-induced apoptosis by control of mitochondrial permeability due to their ability to form channels in membranes and to regulate pre-existing channels (22). In this study, our results revealed that Tanshinone IIA treatment of THP-1 cells up-regulated the expression of Bax as well as down-regulation of Bcl-2.

The caspases are a family of intracellular cysteine proteases with specificity for aspartic acid residues $(23,24)$. Two of these groups, named 'initiator' and 'effector' caspases, play important roles in the apoptotic process $(25,26)$. Caspase- 3 is one of the most important executioners which is capable of cleaving many important cellular substrates (27), and caspase-3 mediated cell death plays an important role in pathogenesis and therapy of a variety of hematological malignancies (26-28).

Survivin, a member of apoptosis inhibitor family, is expressed in most human malignancies and implicated in mitosis regulation and preservation of cell viability (29). Previous data have revealed that survivin is one of the genes most consistently overexpressed in tumor cells which plays important roles in both cell proliferation and cell death (30), down-regulation of survivin expression may lead to programmed cell death (31), indicating that survivin may be an appealing new target for novel therapy in cancer (32). Our results showed that Tanshinone IIA may trigger apoptosis on THP-1 cells via activation of caspase-3 and down-regulation of anti-apoptosis protein Bcl-2 and survivin levels.

In summary, our results demonstrated that Tanshinone IIA has significant antiproliferation effects on THP-1 cells by induction of apoptosis, and that Tanshinone IIA induced apoptosis on THP-1 cells is mainly related to the disruption of $\Delta \psi \mathrm{m}$ and activation of caspase-3 as well as downregulation of anti-apoptotic protein $\mathrm{Bcl}-2$ and survivin as well as up-regulation of pro-apoptotic protein Bax. The results indicate that Tanshinone IIA may serve as a potential anti-leukemia reagent.

\section{Acknowledgements}

We thank the members of our laboratories for their insight and technical support. This work is supported by the grants from National Natural Foundation of P.R. China (No.30570786, No.30770782) and Guangdong Natural Science Foundation of P.R. China (No.8151008901000128) as well as Supported by Program for New Century Excellent Talents in University (No. NCET-06-0721).

\section{References}

1. Boon $\mathrm{H}$ and Wong $\mathrm{J}$ : Botanical medicine and cancer: a review of the safety and efficacy. Expert Opin Pharmacother 5: 2485-2501, 2004.
2. Zhou L, Zuo Z and Chow MS: Danshen: an overview of its chemistry, pharmacology, pharmacokinetics, and clinical use. J Clin Pharmacol 45: 1345-1359, 2005.

3. Wang AM, Sha SH, Lesniak W and Schacht J: Tanshinone (Salviae miltiorrhizae extract) preparations attenuate aminoglycoside-induced free radical formation in vitro and ototoxicity in vivo. Antimicrob Agents Chemother 47: 1836-1841, 2003.

4. Yang LJ, Jeng CJ, Kung HN, Chang CC, Wang AG, Chau GY, Don MJ and Chau YP: Tanshinone IIA isolated from Salvia miltiorrhiza elicits the cell death of human endothelial cells. J Biomed Sci 12: 347-361, 2005.

5. Choi HS, Cho DI, Choi HK, Im SY, Ryu SY and Kim KM: Molecular mechanisms of inhibitory activities of tanshinones on lipopolysaccharide-induced nitric oxide generation in RAW 264.7 cells. Arch Pharm Res 27: 1233-1237, 2004.

6. Wang X, Wei Y, Yuan S, Liu G, Lu Y, Zhang J and Wang W: Potential anticancer activity of tanshinone IIA against human breast cancer. Int J Cancer 116: 799-807, 2005.

7. Yuan SL, Wei YQ, Wang XJ, Xiao F, Li SF and Zhang J: Growth inhibition and apoptosis induction of tanshinone II-A on human hepatocellular carcinoma cells. World J Gastroenterol 10: 2024-2028, 2004.

8. Rossi D and Gaidano G: Messengers of cell death: apoptotic signaling in health and disease. Haematologica 88: 212-218, 2003.

9. Tsuruo T, Naito M and Tomida A: Molecular targeting therapy of cancer: drug resistance, apoptosis and survival signal. Cancer Sci 94: 15-21, 2003.

10. Debatin KM: Apoptosis pathways in cancer and cancer therapy. Cancer Immunol Immunother 53: 153-197, 2004.

11. Yinjun L, Jie J and Weilai X: Homoharringtonine mediates myeloid cell apoptosis via upregulation of pro-apoptotic bax and inducing caspase-3-mediated cleavage of poly(ADP-ribose) polymerase (PARP). Am J Hematol 76: 199-204, 2004.

12. Treasure J: Herbal medicine and cancer: an introductory overview. Semin Oncol Nurs 21: 177-183, 2005.

13. Chan TY: Interaction between warfarin and danshen (Salvia miltiorrhiza). Ann Pharmacol 35: 501-504, 2001

14. Yokozawa T and Chen CP: Role of Salvia miltiorrhiza radix extract and its compounds in enhancing nitric oxide expression. Phytomedicine 7: 55-61, 2000.

15. Zhou GY, Zhao BL, Hou JW, Ma GE and Xin WJ: Protective effects of sodium tanshinone IIA sulphonate against adriamycin-induced lipid peroxidation in mice hearts in vivo and in vitro. Pharmacol Res 40: 487-491,1999.

16. Mosaddik MA: In vitro cytotoxicity of tanshinones isolated from Salvia miltiorrhiza Bunge against P388 lymphocytic leukemia cells. Phytomedicine 10: 682-685, 2003.

17. Bailey LC, Lange BJ, Rheingold SR and Bunin NJ: Bonemarrow relapse in paediatric acute lymphoblastic leukaemia. Lancet Oncol 9: 873-883, 2008.

18. Cuvelier GD, Vitali AM, Ford JC and Dix DB: Multiple intracranial tumors in Philadelphia chromosome positive acute lymphoblastic leukemia: successful treatment following aggressive supportive care, early cranial radiation, high dose chemotherapy and imatinib. Pediatr Blood Cancer 51: 135-137, 2008.

19. Nicot C: Current views in HTLV-I-associated adult T-cell leukemia/lymphoma. Am J Hematol 78: 232-239, 2005.

20. Levine B, Sinha S, Kroemer G and Manion MK: Bcl-2 family members: dual regulators of apoptosis and autophagy. Autophagy 4: 600-606, 2008

21. Kim YH, Park C, Lee JO, Kim GY, Lee WH, Choi YH and Ryu CH: Induction of apoptosis by piceatannol in human leukemic U937 cells through down-regulation of Bcl-2 and activation of caspases. Oncol Rep 19: 961-967, 2008.

22. Sharpe JC, Arnoult D and Youle RJ: Control of mitochondrial permeability by Bcl-2 family members. Biochim Biophys Acta 1644: 107-113, 2004.

23. Kim R, Emi M and Tanabe K: Caspase-dependent and independent cell death pathways after DNA damage (Review). Oncol Rep 14: 595-599, 2005.

24. Denault JB and Salvesen GS: Caspases: keys in the ignition of cell death. Chem Rev 102: 4489-4500, 2002.

25. Boatright KM and Salvesen GS: Caspase activation. Biochem Soc Symp 70: 233-242, 2003.

26. Qi SN, Yoshida A and Wang ZR: GP7 can induce apoptotic DNA fragmentation of human leukemia cells through caspase3-dependent and -independent pathways. Int J Mol Med 13: 163-167, 2004. 
27. Sercan HO, Pehlivan M, Simsek O, Ates H and Sercan Z: Induction of apoptosis increases expression of non-canonical WNT genes in myeloid leukemia cell lines. Oncol Rep 18: 1563-1569, 2007.

28. Mazumder S, Plesca D, Almasan A, Smolewski P Darzynkiewicz Z and Robak T: Caspase-mediated cell death in hematological malignancies: theoretical considerations, methods of assessment, and clinical implications. Leuk Lymphoma 44: 1089-1104, 2003.

29. Morinaga S, Nakamura Y, Ishiwa N, Yoshikawa T, Noguchi Y, Yamamoto Y, Rino Y, Imada T, Takanashi Y, Akaike M, Sugimasa $\mathrm{Y}$ and Takemiya S: Expression of survivin mRNA associates with apoptosis, proliferation and histologically aggressive features in hepatocellular carcinoma. Oncol Rep 12: 1189-1194, 2004.
30. Nakao K, Hamasaki K, Ichikawa T, Arima K, Eguchi K and Ishii N: Survivin downregulation by siRNA sensitizes human hepatoma cells to TRAIL-induced apoptosis. Oncol Rep 16: 389-392, 2006.

31. Wang J, Xu Z and Zhang M: Downregulation of survivin expression and elevation of caspase-3 activity involved in pitavastatin-induced HepG 2 cell apoptosis. Oncol Rep 18: 383-387, 2007.

32. Giannetti L, Consolo U, Magnoni $\mathrm{C}$ and Lo Muzio L: Apoptosis: escaping strategies in human skin cancer (Review). Oncol Rep 11: 401-405, 2004 